Article

\title{
Government Data Performance: The Roles of Technology, Government Capacity, and Globalization through the Effects of National Innovativeness
}

\author{
Seunghwan Myeong ${ }^{1}{ }^{\mathbb{D}}$, Michael J. Ahn ${ }^{2}$, Younhee Kim ${ }^{3, *}$, Shengli Chu ${ }^{2}$ and Woojong Suh ${ }^{4}$ \\ 1 Department of Public Administration, Inha University, Incheon 22212, Korea; shmyeong@inha.ac.kr \\ 2 Department of Public Policy and Public Affairs, University of Massachusetts Boston, Boston, MA 02125, USA; \\ Michael.Ahn@umb.edu (M.J.A.); shengli.chu001@umb.edu (S.C.) \\ 3 School of Public Affairs, Pennsylvania State University Harrisburg, Middletown, PA 17057, USA \\ 4 Department of Business Administration, Inha University, Incheon 22212, Korea; wjsuh@inha.ac.kr \\ * Correspondence: yzk46@psu.edu; Tel.: +1-717-948-6649
}

check for updates

Citation: Myeong, S.; Ahn, M.J.; Kim, Y.; Chu, S.; Suh, W. Government Data Performance: The Roles of

Technology, Government Capacity, and Globalization through the Effects of National Innovativeness. Sustainability 2021, 13, 12589. https:/ / doi.org/10.3390/su132212589

Academic Editors: Umberto Panniello and Angelo Natalicchio

Received: 10 September 2021

Accepted: 11 November 2021

Published: 15 November 2021

Publisher's Note: MDPI stays neutral with regard to jurisdictional claims in published maps and institutional affiliations.

Copyright: (c) 2021 by the authors. Licensee MDPI, Basel, Switzerland. This article is an open access article distributed under the terms and conditions of the Creative Commons Attribution (CC BY) license (https:/ / creativecommons.org/licenses/by/ $4.0 /)$.

\begin{abstract}
The availability of open, relevant, and up-to-date public data is becoming an increasingly important dimension of national competitiveness and sustainable development. It serves as a foundation for novel technologies, such as big data analytics, machine learning, and artificial intelligence, to take root and flourish, and it can help improve the quality and efficiency of government decision making and render governments more transparent and accessible to the public. Often referred as Open Government Data, or OGD, governments around the world have committed resources to constructing various OGD platforms. However, building a robust and effective OGD system has proved difficult, as the promise of OGD has not been realized fully around the world. At this important juncture, this study aims to explore the relationship between national technological and organizational capacities and environmental factor and the quality of OGD systems. In addition, national innovativeness and the degree of "globalization" in a country and their moderating effects between the predictors and OGD performance are examined. Our findings indicate strong positive effects of national technological capacity, government organization capacity, and globalization on OGD quality and a positive moderating effect of national innovativeness.
\end{abstract}

Keywords: innovation; moderating effects; open government data; technology-organizationenvironment framework

\section{Introduction}

The increasing availability of public government data offers internal and external stakeholders a broad range of opportunities. Often coined as Open Data (OD) or Open Government Data (OGD), this increasing practice of making government data open and available to the general public aims to create a more transparent and accessible government. In addition, OGD enables the government, citizens, businesses, and researchers to understand various public and social problems in a novel way and allows the government to use advanced and emerging information technologies (e.g., big data analytics, machine learning, and artificial intelligence) to facilitate a more effective and efficient government decision-making process. The open nature of OGD can promote citizen participation, government transparency, and service delivery [1-8] as key paths to sustainable development [9-12].

With the rising demand for OGD, governments around the world have devoted resources to building open government data platforms. However, they face various challenges in establishing effective open government data systems, and the promise of open government data has not been sufficiently realized across countries $[13,14]$. With the backdrop of increasing open data practice around the world, this study aims to determine the performance of OGD systems using the technology-organization-environment (TOE) 
framework [15] and explore the moderating effect of the national innovative capacity ("innovativeness") between the TOE dimensions and OGD performance using panel data across 115 countries from 2013 to 2016 [16-19]. In the following section, this study explores the literature on OGD definitions and concepts, existing OGD evaluation models, and key factors that are thought to determine the performance of OGD. Then, this study introduces our theoretical framework, data and methodology, and discusses the findings from the analysis.

\section{Literature Review}

In this section, we will first examine three main research trends related to OGD. The first section will provide various definitions of open data as well as different initiatives and polices associated with opening government data across the world. The second section provides an overview of different open data evaluation models. The last section will discuss the determinants and factors that impact the performance of open data.

\subsection{Open Government Data: Definitions and Concepts}

There are several ways to define Open Data, however, the main concepts are similar. The Open Data Handbook describes Open Data as "data that can be freely used, reused and redistributed by anyone- subject only, at most, to the requirement to attribute and share alike" [20]. In 2013, the Office of Management and Budget (OMB) stated "Open data refers to publicly available data structured in a way that enables the data to be fully discoverable and usable by end users" [21]. Similarly, Data.Gov.UK defines Open Data as "Open data is data that is published in an open format, is machine readable and is published under a license that allows for free reuse", and the Open Data Institute defines the term as "information that is available for anyone to use, for any purpose, at no cost."

A set of general principles for open data has been established even though there are many definitions. In 2007, 30 leading open government advocates agreed that open government data should comply with eight principles, the data should be: complete, primary, timely, accessible, machine processable, non-discriminatory, nonproprietary, and license-free. In sum, the main concepts of these eight principles emphasize that: (1) "Government data is any data and information produced or commissioned by public bodies"; and (2) "Open data are data that can be freely used, re-used and distributed by anyone, only subject to (at the most) the requirement that users attribute the data and that they make their work available to be shared as well" [22].

In recent decades, the concept of "Open Government Data" has become a global trend among public and private sectors, leading countries such as the USA, Australia, China, and South Korea to set it as an important development agenda [23]. The Office of the Australian Government claims that information is considered the "lifeblood of a robust democracy and productive economy [24]". Governments and societies have gradually increased their appreciation of accessing public sector information and are following the trend of opening data due to pressure for increasing transparency in public sectors and sustaining good governance. In 2003, the EU introduced the first legislative initiative of reusing and opening public sector information, aiming to remove barriers and make information available to reuse [25]. This directive was further developed in the following years, setting "opening by default" as one of the foundational principles. This inspired more organizations and institutions to open data to the public, leading to a boost in the data market that can take advantage of open information and big data technologies [25].

It also led to the dramatic increase in the number of open data initiatives, from 2 to over 200 between 2009 and 2014 as well as membership in the Open Government Partnership (OGP), from 8 to 69 from 2011 to 2016. The USA, as another OGD leader, released a Memorandum on Transparency and Open Government and formed open government federal policies during President Obama's administration in 2009, defining three foundational principles: transparency, participation, and collaboration [26-28]. Advantages of opening data can be found across many different dimensions. Researchers and practitioners have 
demonstrated the considerable benefits of opening government data for various stakeholders such as citizens, business, researchers to understand public or private problems in a novel way with advanced data technology $[29,30]$.

Furthermore, opening data can contribute to obtaining and integrating required information in a more effective and efficient way, which leads to a faster transition to a knowledge-based and technology-based economy and society. From a broader perspective, Open Government Data have the potential to increase economic development, government transparency, and accountability, as well as to promote civil engagement [31].

\subsection{Different OGD Evaluation Models}

There is no single rule to address the performance of opening government data. Researchers have continued to explore different evaluation models from various dimensions throughout the years. The earliest evaluation study on OGD was published by Perez and his colleagues in 2005. By analyzing European government financial data, the study provided extensive evidence of the advantages of web-based data, which remain applicable to a broader concept of Open Government Data [32]. This study motivated Open Government Data related organizations to finalize the principles and guidelines for data providers and publishers [33].

While previous studies basically focused on providing principles and guidelines, more recent research has started to provide detailed operational methods for evaluating open government data. For example, The Open Data Index focuses on data quality and standards by analyzing factors such as machine-readable format, data availability, free use, license, and data quality [20]. The New York Metropolitan Transportation Council used a more comprehensive model, addressing open data performance by exploring accuracy, objectivity, believability, reputation, accessibility, access security, relevancy, valueadded, timeliness, completeness, amount of data, interpretability, ease of understanding, concise representation, consistent representation, appropriateness of format, feedback, and user support [34]. Vetro et al utilized datasets from Italy's national and city portals and conducted quantitative assessment based on seven criteria: completeness, traceability, currentness, compliance, expiration, understandability, and accuracy [35].

The Open Data Barometer evaluates OGD through a model based on the readiness of various stakeholders such as government, the public, and enterprise; open data implementation such as the availability of data sets, innovative data usage and data categories; as well as its social, political, and economic impacts [36]. Louyrenco compared seven international portals by analyzing their characteristics of data disclosure, quality, completeness, access and visibility, usability and comprehensibility, timeliness, value and usefulness, and granularity and comparability [37]. Nahon et al. explored 16 US portals based on the factors of use coverage, rhythm, categorization, and feedback [38]. Donker and Loenen analyzed the OGD ecosystem by evaluating criteria such as data supply and open data governance as well as open data user characteristics [39]. The Open Data Maturity report, released by the EU in 2018, analyzed 28 European countries based on four aspects: open data policy, open data portal, open data impact, and open data quality [40]. Moreover, Ahn and Chu introduced an evaluation model including aspects of government managerial capacity and political and legal environment, borrowing concepts from Rosenbloom's public administration evaluation approaches [22]. These different models provide us a comprehensive understanding of current trends in and the performance of OGD.

\subsection{Determinants of Opening Data}

The concept of open government is multidimensional, including accessibility, transparency, and participation [41-43]. Based on this concept, scholars have categorized the determinants that impact the performance of OGD into internal organization variables and external environmental variables $[43,44]$, which include structural organizational determinants [45], cultural organizational determinants [46], and external environmental determinants [47]. 
Organizational capacity, technological capacity, and a centralized decision-making model are the three main factors of structural organizational determinants. The first structural determinant of innovation adoption is organizational capacity, which means that organizations with higher capacity may be able to afford innovations more easily and may have more freedom to experiment with innovation, since Moon and Norris suggest that organizational capacity is positively related to e-government implementation and progress and claim that organizational capacity is critical to open government initiatives [48].

The second structural determinant is technological capacity. The availability of technological capabilities and expertise in an organization is important to different levels of opening government [49], and Layne and Lee argue that in order to fully open government data, governments must develop advanced technologies. The third structural determinant is the decision-making model in organizations [50]. Hall suggests that a centralized organizations may limit the contribution of individual employees [51], and Damanpour claims that centralization has a negative impact on innovation adoption since there is less room to experiment with new technologies, which makes it less likely for centralized organizations to be accessible and transparent $[43,52]$.

Work routines, innovation culture, and external stakeholders are the three main factors of cultural determinants. Grimmelikhuijisen and Feeney claim that a civil servant in an organization with strong routines may insist on maintaining a stable work environment and may be less used to risk taking, which have a negative relation to the adoption of open government [43]. An innovation climate in an organization may enhance their adoption level of opening government. Moon and Norris argue that innovation-oriented governments tend to adopt new managerial and technological approaches faster. Being open to external stakeholders is the third cultural determinant [48]. Mahler suggests that a culture of openness to external stakeholders may contribute to the likelihood of open government adoption [53].

Competition, coercive pressures, normative pressures, learning, and the political environment are the five factors of external environmental variables. Competition between governments may result in more open and transparent government $[47,54]$. Coercive regulations and vertical political mandates also put pressure on governments to adopt particular innovations [55,56]. The culmination of common practices, values, and norms can also put pressure on opening government. Observing the experience of peer governments and learning from them also can impact the adoption of innovation. Furthermore, political competition could foster open government because it represents political power [57].

\section{Theoretical Framework and Analysis Framework}

In this section, we will explore the organizational level of innovation as well as a broader dimension: the policy level of innovation for opening government data. We will first introduce the theoretical framework that guides our study: the TOE framework, known as Technology, Organization, and Environment, affecting the application of technology. Moreover, national innovativeness is also considered as another driving determinant in this research. An analysis framework will be introduced to show the relationships between Open Data performance, these determinants, and how they influence the performance of OGD.

\subsection{Theoretical Framework}

\subsubsection{Technology-Organization-Environment (TOE) Framework}

The TOE framework has been influential in explaining organizational adoption and application by emphasizing the combined influence of technological, organizational, and environmental factors $[8,15,58]$. The first component, technological factors, refers to Information and Communication Technology (ICT) infrastructure, including the characteristics of the technology itself and its relationship to the organization, focusing on the goodness of fit of technology with the structural characteristics of the organization as well as the application capability of the organization [59]. The second component of organizational 
factors is government capacity often defined by the quality of regulation, the rule of law, organizational characteristics and resources, organizational size, formal/informal institutional arrangements, and communication mechanisms [60]. The environmental factors include aspects such as globalization, market structure, demand pressures, and institutional environment.

\subsubsection{Policy Innovation and Open Government Data}

Grimmelikhuijisen and Feeney integrate and test theories on policy innovation diffusion [55] and innovation adoption $[49,57]$ in order to explain different dimensions of open government such as accessibility, transparency, and participation. The definition of policy innovation adoption is something new to the adopting organization [60], and this new idea requires "up-front expenditure" of resources and a major change from established routines [59]. Open government can be considered as a form of public sector innovation, since it requires governments to adopt new technology, develop different relationships with stakeholders, and accept potential risks.

Furthermore, organizations may experience pressure from the external environment and deliberate organizational decision making that may push organizations to innovate. The innovation adoption theory argues that it is a way to adapt in order to maintain or improve organizational performance [56,57]. The policy innovation diffuse theory explains that competition, normative pressure, coercion, and learning are mechanisms that cause states to adopt policies developed in other jurisdictions [55]. To apply this theory to the open data case, governments that do not remain competitive and adopt innovations may lag behind their peers. For this reason, different levels of government may respond to pressures from the external environment to become more open as well as more transparent, accessible, and participatory.

\subsection{Analysis Framework and Hypotheses}

Most existing research only focuses on either organizational technology innovation or policy level innovation. Our research combines these two different dimensions of innovation to address the evaluation of open government data. We constructed an analysis framework based on the TOE and Policy Innovation frameworks, as shown in Figure 1. Factors such as technical condition, organizational capacity, global environment, and policy innovation work together to influence the performance of open government data. Hypotheses based on each determinant in the framework will be discussed in the following sections.

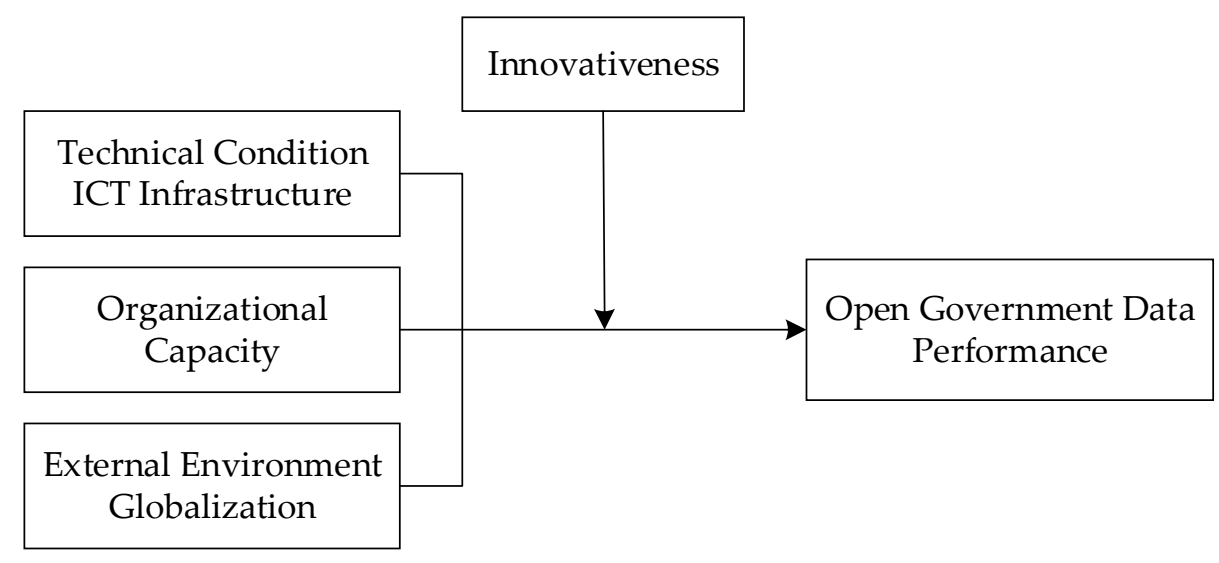

Figure 1. Analysis Framework.

\subsubsection{Technical Condition: ICT Infrastructure}

The technical condition refers to the organization's technical ability to organize information technologies. As government data openness involves data generation, data collection, data distribution, and data usage, data openness is closely associated with the technological aspect [9]. Governments face many technical challenges in the implemen- 
tation of open government data. A low data collection rate, low machine-readable data, unintegrated database, and less standardized data hinder the further improvement of government data openness [61]. Appropriate ICT infrastructure, efficient data collection, data cleansing techniques, and comprehensive data management technology systems play a significant role in the success of open government data practices [62]. One empirical study found that the ICT infrastructure level significantly correlated with government transparency through opening data in 122 countries [63]. Therefore, having a data infrastructure is a foundation to implement open government data.

Hypothesis 1 (H1). A higher level of the nation's ICT infrastructure will be associated with a higher level of open government data.

\subsubsection{Organizational Condition: Government Capacity}

Maintaining open government data is not just a technical issue. Technology is a means to achieve a goal, and it is important to explore other important factors to avoid falling into technical determinism. Open data applications and practices are influenced by organizational forms, institutional arrangements, administrative processes, and organizational culture influence [64]. Studies found that the culture of organizational support, organizational compatibility, and fairness and innovation play a positive and significant role in open government data practices [65-67]. Due to the influence of a conservative culture, government departments tend to choose not to disclose data or to disclose fewer data in specific practices to avoid responsibility.

An effective legal system is a gatekeeper to avoid violations and protect the security of public data [68]. A vague legal framework and the lack of institutional standards will decrease the willingness to open government data, restrict data value transformation, and cause implementation of inappropriate methods [69]. A more mature institutional environment increases the probability of adopting open government data policies [70]. Open government data involve multi-departmental collaboration issues, so institutional norms help agencies clarify authority and responsibility, establish collaboration mechanisms, and ensure practical interagency collaboration [13]. The legal system would strictly enforce all levels of government and directly contribute to open government data, ignoring the fragmentation and selective implementation logic of local governments in implementation. These ideas inspire us to adopt a more comprehensive and multilevel theoretical perspective and analyze the complex mechanisms affecting open government data in more depth.

Open government data are under pressure from "stock opening" and "incremental opening", which requires strong government capacity to provide sufficient resources, appropriate systems, and efficient execution to promote open government data. A case study on open government data in the Philippines found that the lack of government capacity has led to the emergence of untimely data updates, the inability to perform online statistical analysis, and the absence of a typical release mechanism [71]. The finding claimed that government capacity is a crucial factor affecting the level of open government data. Government capacity in this study was defined as the ability to effectively formulate, implement, and test open government data policies and practices. As a result, government capacity should lead to increasing open government data.

Hypothesis 2 (H2). A higher level of government capacity will be positively associated with a higher level of open government data.

\subsubsection{External Environment: Globalization}

As organizations are embedded in the social environment, their fundamental goals are to adapt, survive, and develop their institutional settings to the changing environment [72]. Grounded by institutionalism, pressure from peers and superiors, public pressure, and competitive pressure significantly impact the level of open government data [73-77]. Glob- 
alization has provided the necessary conditions for the open government data movement. The example of open government data construction in Saudi Arabia presented how international standards for open government data can encourage the country to learn about and promote an increased level of open government data development [78]. This case indicates that international standards of open government data as an external environment would pressure countries to align their open data development with international trends.

The McKinsey Global Institute termed this diffusion phenomenon as "digital globalization [60]". The greater the degree of globalization, the greater the pressure on a country to increase the level of open government data, which will lead to the strengthening of open government data construction and an increase in the level of open government data in that country. Globalization is driving governments to compete, learn, and imitate around open government data. This study an effect of globalization on open government data.

Hypothesis 3 (H3). A higher level of globalization will be associated with a higher level of open government data.

\subsubsection{The Moderating Effects of Innovation}

National innovativeness, or "innovation", is an essential driver for the continued openness of government data $[5,61]$. Countries such as the UK and the US hold open government data application and design competitions every year to encourage innovation and apply the best entries to public services, which significantly contributes to open government data. Innovation has been constructed in a wide array of measures. The narrow definition of innovation was characterized as the commercialization of technological innovation [79]. Innovation capacity as soft power creates more socioeconomic value for data utilization, which results in the improvement of open government data through interacting with other predictors.

Adopting a broader view of innovation and being able to establish innovative policies on OGD can lead to a better result in its performance. A country's capacity for innovation reflects its ability to transform ideas into new products, services, and policies. According to Schumpeter's innovation theory, the more innovative an organization is, the better it can adapt to changes in the external environment, and the higher its capacity and performance. Innovation capacity can effectively interact with ICT infrastructure, government capacity, and globalization to improve open government data. Together, this study suggests that the innovation level should moderate the relationship between the TOE dimensions and open government data.

Hypotheses $4 \mathbf{4 a}-4 \mathbf{c}(\mathbf{H} 4 \mathbf{a}-\mathbf{H} 4 \mathbf{c})$. A innovation level will moderate the relationship between the TOE dimensions - (a) ICT infrastructure, (b) government capacity, and (c) globalization-and open government data.

\section{Methods}

\subsection{Data and Meaures}

The data in this study were collected from several sources from 2013 to 2016, including the Open Government Data Barometer provided by the World Wide Web Foundation, the United Nations e-Government Survey, the Governance Index published by the World Bank, the Global Competitiveness Index reported by the World Economic Forum, the World Globalization Report published by the Swiss Federal Institute of Technology Zurich, and the World Development Report. The unbalanced panel data were extracted from 115 countries.

The performance of OGD as a dependent variable was defined as the actual status and stage of open public data development reported by the Open Government Data Barometer which comprehensively assessed a country's open government data readiness, implementation, and impact. The ICT infrastructure variable as a proxy measure of technological capacity was measured by the degree of e-government quality assessed by the United Nations e-Government study. The government organizational capacity variable 
is an aggregate of six governance dimensions (i.e., accountability, political stability, control of corruption, government performance, quality of regulation, and rule of law) reported by the Worldwide Governance Indicators project [80]. Using an aggregated measure of governance is considered a better indicator than the individual governance measures [81]. The globalization variable was measured by the Globalization Index that assessed the extent of political, economic, and social globalization in a country published by the Swiss Federal Institute of Technology Zurich.

The moderating variable, innovation, was measured by the innovation pillar from the Global Competitiveness Index report published by the World Economic Forum [82]. It is often used to measure the level of technological innovation and included capacity for innovation, quality of scientific research institutions, company spending on R\&D, university-industry collaboration in R\&D, government procurement of advanced technology products, availability of scientists and engineers, and patent applications. At the country level, lagging the independent and moderating variables were suggested for empirical validation [83]. Thus, we lagged both variables by one year prior to the base year compared to the dependent variable to control the time impact. Previous studies noted that a country's economic development heavily determined government operating resources $[84,85]$. Therefore, Gross Domestic Product per capita was used to control for such variation.

\subsection{Empirical Analysis}

This study employed moderated regression analysis to test the role of innovation in the relationship between three predictors and open government data. Three panel data regression models were tested in this study. All three predictors in Step 1 (Model 1) and the moderator with three predictors in Step 2 (Model 2) were included. Model 3 included all the predictors, the interaction terms, and the control variable. As three interaction terms were included in our model, the presence of multicollinearity among main effects and interaction terms was carefully tested with the variance inflation factor (VIF). All VIF scores were below 5 , so the results indicated that no corrective measures were necessary.

We ran the Hausman test to detect model misspecification between a fixed effects model and a random effects model with panel data. The result of the Hausman test confirmed that a fixed effects model was significantly consistent at the one percent level to estimate the unbiased effects of independent variables controlling omitted variable bias with interactive terms in this study [86].

\section{Results}

Table 1 summarizes the descriptive statistics of the data. The average openness of government data score across 370 countries was 33.17. The overall openness was relatively low, especially in data security, regulatory system, and data ecology. The gap between the highest and the lowest score of open government data was wide from 0 to 100, even within the developed countries group. As such, the open data movement in governments across countries seemed to be slowly moving forward to make government more accountable and transparent. The innovation measure scaled from 1 (not at all) to 7 (to a great extent) averaged 3.664.

The mean value of ICT infrastructure development was close to the midpoint and ranged from 0.03 to 1 . The results indicated that more governments adopted ICT to deliver public services, but variations among countries remained. The government capacity measure was scaled from -2.5 to 2.5 , with higher values representing better governance. The average government capacity for the data period was 0.192 , which indicated little improvement in the world average of government capacity. The average index of globalization scaled from a minimum of 1 to a maximum of 100 was 68.83 . The ranges of globalization scores in this study varied across countries. 
Table 1. Descriptive statistics of variables.

\begin{tabular}{ccccc}
\hline Variables & Mean & SD & Min. & Max. \\
\hline Openness of government data & 33.17 & 23.61 & 0 & 100 \\
ICT infrastructure & 0.499 & 0.262 & 0.03 & 1.00 \\
Government capacity & 0.192 & 0.916 & -1.62 & 1.87 \\
Globalization & 68.83 & 13.18 & 38.84 & 91.31 \\
Innovation & 3.664 & 0.920 & 1.89 & 5.79 \\
Economic development $(\log )$ & 9.48 & 1.18 & 6.77 & 11.76 \\
\hline
\end{tabular}
Note: $N=370$.

The regression results are presented in Table 2. In Model 1, the $R^{2}$ value of 0.692 $(F=240.365, p<0.001)$ indicated that the overall model sufficiently explained the variance in open government data. The main effects of all three independent variables were positively significant for open government data at the 0.01 level. An advanced ICT infrastructure, higher organizational capacity, and intensive globalization made governments more open, consistent with previous research $[62,64,78]$. The highest predictor of the level of open government data among those variables was ICT infrastructure. Open government data practice involves complex technical issues including data standards, data warehouses, and data integration, so technological advancement would be a significant driving force. Although this study did not hypothesize the direct effect of innovation on open government data, Model 2 presented the supporting result of innovation on open government data at the 0.05 level, which is consistent with existing studies [14].

Table 2. Regression analysis for the interaction of innovation.

\begin{tabular}{cccc}
\hline Variables & Model 1 & Model 2 & Model 3 \\
\hline Government capacity & $10.117^{* * *}$ & $7.809^{* * *}$ & $16.293^{* *}$ \\
Globalization & $(1.509)$ & $(1.924)$ & $(1.611)$ \\
& $14.003^{* * *}$ & $4.200^{* * *}$ & $6.083^{* *}$ \\
Moderator (Innovation) & $(3.561)$ & $(1.113)$ & $(1.751)$ \\
Interaction effects & & $3.694^{* *}$ & $9.186^{* *}$ \\
ICT infrastructure $\times$ Innovation & & $(1.336)$ & $(2.930)$ \\
Government capacity $\times$ Innovation & & & $6.067^{* *}$ \\
Globalization $\times$ Innovation & & & $(3.881)$ \\
Economic development (control) & $6.045^{* * *}$ & $6.604^{* * *}$ & $15.810^{* * *}$ \\
$R^{2}$ & $(1.449)$ & $(1.449)$ & $3.402)$ \\
$F$ & $0.692^{* * *}$ & 0.705 & $\left(1.038^{* *}\right.$ \\
$R^{2}$ Change & & $210.800^{* * *}$ & $1.453)$ \\
$F$ Change & $240.365^{* * *}$ & 0.003 & 0.720 \\
& & $30.565^{* * *}$ & $81.165^{* * *}$ \\
\hline
\end{tabular}

Notes: $N=370$; ${ }^{* *} p<0.05,{ }^{* * *} p<0.01$; standard deviations in parentheses; $R^{2}$ Change indicates the increases in $R^{2}$ in the model from the previous model.

The change in $R^{2}$ value from Model 2 to Model 3 was 0.015 indicating that the constructed interactive model for testing moderation effects could explain the hypothesized relationships in this study. The addition of the moderating effects of innovation significantly increased 1.5 percent of the explanation of variance in open government data. As hypothesized (H1), ICT infrastructure and innovation (H4a) significantly interacted to predict open government data at the 0.05 level. The result confirmed that the positive relationship between ICT infrastructure and open government data was strong when the innovation capacity was high; the effect of ICT infrastructure was amplified by the country's innovativeness. In addition, government capacity $(\mathrm{H} 2)$ and innovation $(\mathrm{H} 4 \mathrm{~b})$ significantly interacted with open government data at the 0.01 level. The result indicated 
strong evidence for the positive effect of government capacity on OGD performance and a strong moderating effect of innovation in this relationship.

However, the predicted interaction of globalization (H3) was not confirmed, although the coefficient indicated a positive relationship. Innovation did not have any significant moderating impact on this relationship either.

\section{Discussion}

Our findings showed that ICT infrastructure was a necessary condition, rather than a sufficient condition, as the government's organizational capacity matters significantly in maintaining a high performance OGD system. Postulated by the TOE framework, external pressures, measured in the degree of globalization, exert significant impact on OGD systems. Taking globalization into our conceptual model to analyze the level of open government data at the country level was helpful in understanding how countries with inadequate ICT infrastructure and economic development may become aware of their open government status and prompt them to leverage their resources and programs to achieve a better Open Government Data system.

Our analysis confirmed the significant moderating effects of innovation on the national ICT infrastructure and government organizational capacity. A well-developed ICT infrastructure and high-performing governmental organizations in a country considerably improved the performance of OGD, whose effects were amplified by the country's innovative capacity $[62,65,66,87]$. Notably, the moderating effect of innovation with government capacity was much stronger than with ICT infrastructure indicating the importance of the government's organizational performance rather than the nation's technological capacity. On the other hand, the impact of globalization was dissipated when innovation took effect in the model highlighting the comparative significance of national innovativeness over the degree of globalization in the country. In both cases, our study found that national innovativeness had a significant influence on OGD performance directly and through TOE factors.

\section{Conclusions}

Opening government data is a critical element of modern government in our complex, connected, and globalized world with the emergence of novel and potentially disruptive technologies such as big data analytics, machine learning, cloud computing, and various forms of artificial intelligence. OGD enables these new technologies to develop and mature opening a potential pathway to a smart and AI-augmented digital government. It also allows for more accessible and accountable government with increased data transparency. This study found that ICT infrastructure, a government's organizational capacity, and environmental characteristics (globalization) all had positive and significant impacts on OGD performance. Consistent with previous studies [62], this study implies that the ICT infrastructure facilitates robust OGD systems and promotes efficient data production, sharing, control, and data applications. ICT infrastructure serves as an important necessary condition for successful OGD implementation.

This study expanded our understanding of factors that affect the performance of OGD systems at the national level by applying the TOE framework and national innovativeness. However, the limitation of our data, being relatively broad and abstract, prevented us from looking deeper into this emerging practice. Examining our model with data with greater details about each nation would shed more light on the nature of the relationships identified in our study. Lastly, future study should examine the OGD phenomenon with more recent data to reflect the rapidly changing technological landscape.

Author Contributions: Conceptualization, S.M.; methodology, S.M. and W.S.; validation, Y.K. and M.J.A.; formal analysis, W.S. and Y.K.; writing-original draft preparation, S.M., M.J.A. and Y.K.; writing-review and editing, S.M., M.J.A., Y.K. and S.C.; funding acquisition, S.M. All authors have read and agreed to the published version of the manuscript. 
Funding: This research was funded by the Ministry of Education of the Republic of Korea and the National Research Foundation of Korea (NRF-2019S1A5C2A0381234) and the Ministry of Trade, Industry, and Energy of the Republic of Korea (MOTIE-P0008703).

Informed Consent Statement: Not applicable.

Data Availability Statement: No new data were created in this study. Data sharing is not applicable to this research.

Conflicts of Interest: The authors declare no conflict of interest.

\section{References}

1. Gonzalez-Zapata, F.; Heeks, R. The multiple meanings of open government data: Understanding different stakeholders and their perspectives. Gov. Inf. Q. 2015, 32, 441-452. [CrossRef]

2. Dawes, S. Stewardship and usefulness policy principles for information-based transparency. Gov. Inf. Q. 2010, 27, 377-383. [CrossRef]

3. Fan, B.; Zhao, Y. The moderating effect of external pressure on the relationship between internal organizational factors and the quality of open government data. Gov. Inf. Q. 2017, 34, 396-405. [CrossRef]

4. Abu-Shanab, E.A. Reengineering the open government concept: An empirical support for a proposed model. Gov. Inf. Q. 2015, 32, 453-463. [CrossRef]

5. Dawes, S.S.; Vidiasova, L.; Parkhimovich, O. Planning and designing open government data programs: An ecosystem approach. Gov. Inf. Q. 2016, 33, 15-27. [CrossRef]

6. Ruijer, E.; Grimmelikhuijen, S.; Meijer, A. Open data for democracy: Developing a theoretical framework for open data use. Gov. Inf. Q. 2017, 34, 45-52. [CrossRef]

7. Ruijer, E.; Meijer, A. Open government data as an innovation process: Lessons from a living lab experiment. Public Perform. Manag. Rev. 2020, 43, 613-635. [CrossRef]

8. Jiang, H.; Shao, Q.; Liou, J.J.H.; Shao, T.; Shi, X. Improving the sustainability of open government data. Sustainability 2019, 11, 2388. [CrossRef]

9. United Nations Department of Economic and Social Affairs. United Nations E-Government Survey 2016; United Nation Department of Economic and Social Affairs: New York, NY, USA, 2016.

10. Seo, H.; Myeong, S. Determinant factors for adoption of government as a platform in South Korea: Mediating effects on the perception of intelligent information technology. Sustainability 2021, 13, 10464. [CrossRef]

11. Park, E.G. How to improve government openness for sustainable development: The interaction of four factors in African countries. Sustainability 2021, 13, 8000. [CrossRef]

12. Open Knowledge Foundation. The Open Data Handbook. 2012. Available online: http://opendatahandbook.org/pdf/ OpenDataHandbook.pdf (accessed on 13 November 2021).

13. Barry, E.; Bannister, F. Barriers to open data release: A view from the top. Inf. Polity 2014, 19, 129-152. [CrossRef]

14. Meijer, A. E-governance innovation: Barriers and strategies. Gov. Inf. Q. 2015, 32, 198-206. [CrossRef]

15. Baker, J. The technology-organization-environment framework. In Information Systems Theory; Dwivedi, Y.K., Wade, M.R., Schneberger, S.L., Eds.; Springer: Berlin, Germany, 2011; Volume 1, pp. 231-245.

16. Safarov, I.; Meijer, A.; Grimmelikhuijsen, S. Utilization of open government data: A literature review of types, conditions, effects and users. Inf. Polity 2017, 22, 1-24. [CrossRef]

17. Zuiderwijk, A.; Janssen, M. Open data policies, their implementation and impact a framework for comparison. Gov. Inf. Q. 2014, 31, 17-29. [CrossRef]

18. World Economic Forum. The Global Competitiveness Index Dataset 2007-2016; World Economic Forum: Geneva, Switzerland. Available online: https:/ / www3.weforum.org/docs/GCR2016-2017/05FullReport/TheGlobalCompetitivenessReport2016-20 17_FINAL.pdf (accessed on 13 November 2021).

19. Cao, X.; Deng, M.; Song, F.; Zhong, S.; Zhu, J. Direct and moderating effects of environmental regulation intensity on enterprise technology innovation: The case of China. PLOS ONE 2019, 14, e223175. [CrossRef]

20. Burwell, S.; VanRoekel, S.; Park, T.; Mancini, D. Memorandum for the Heads of Executive Departments and Agencies, M-13-13, Open Data Policy-Managing Information as an Asset; Director Executive Office of the President, Office of Management and Budget: Washinton, DC, USA, 2013.

21. Ubaldi, B. Open Government Data: Towards Empirical Analysis of Open Government Data Initiatives; OECD Working Papers on Public Governance; OECD Publishing: Paris, France, 2013; Volume 22. [CrossRef]

22. Wirtz, B.; Birkmeyer, S. Open Government: Origin, Development, and Conceptual Perspectives. Int. J. Pub. Admin. 2015, 38, 381-396. [CrossRef]

23. Office of the Australian Information Commissioner. Open Public Sector Information: From Principles to Practice. Available online: https:/ /apo.org.au/sites/default/files/resource-files/2013-02/apo-nid32959.pdf (accessed on 13 November 2021). 
24. European Union. Directive 2013/37/EU of the European Parliament and of the Council of 26 June 2013 Amending Directive 2003/98/EC on the Re-Use of Public Sector Information. EUR-Lex [online]. 26 June 2013 [cit.2013-08-23]. Available online: http:/ / eur-lex.europa.eu/LexUriServ/LexUriServ.do?uri=OJ:L:2013:175:0001:0008:CS:PDF (accessed on 13 November 2021).

25. Ganapati, S.; Reddick, C.G. Open e-government in US state governments: Survey evidence from chief information officers. Gov. Inf. Q. 2012, 29, 115-122. [CrossRef]

26. McDermott, P. Building open government. Gov. Inf. Q. 2010, 27, 401-413. [CrossRef]

27. Jaeger, P.T.; Bertot, J.C. Transparency and technological change: Ensuring equal and sustained public access to government information. Gov. Inf. Q. 2010, 27, 371-376. [CrossRef]

28. Susha, I.; Zuiderwijk, A.; Janssen, M.; Grönlund, A. Benchmarks for Evaluating the Progress of Open Data Adoption: Usage, Limitations, and Lessons Learned. Soc. Sci. Com. Rev. 2015, 33, 613-630. [CrossRef]

29. Zuiderwijk, A.; Janssen, M. A Coordination Theory Perspective to Improve the Use of Open Data in Policy-Making. In Proceedings of the International Conference on Electronic Government, Koblenz, Germany, 16-19 September 2013; Lecture Notes in Computer Science. Volume 8074, pp. 38-49. [CrossRef]

30. Pew Research Center. Americans' Views on Data to Open Government. 2015. Available online: http:/ / www.pewinternet.org/20 15/04/21/open-government-data/ (accessed on 13 November 2021).

31. Pérez, C.C.; Hernández, A.M.L.; Bolívar, M.P.R. Citizens' access to on-line governmental financial information: Practices in the European Union countries. Gov. Inf. Q. 2005, 22, 258-276. [CrossRef]

32. W3C. Data on the Web Best Practices. Available online: https://www.w3.org/TR/dwbp/ (accessed on 8 February 2021).

33. Ozmen-Ertekin, D.; Ozbay, K. Dynamic data maintenance for quality data, quality research. Int. J. Inf. Manag. 2012, 32, $282-293$. [CrossRef]

34. World Wide Web Foundation. Open Data Barometer Global Report. 2015. Available online: http:/ / www.opendataresearch.org/ barometer (accessed on 13 November 2021).

35. Lourenço, R.P. An analysis of open government portals: A perspective of transparency for accountability. Gov. Inf. Q. 2015, 32, 323-332. [CrossRef]

36. Nahon, K.; Peled, A.; Shkabatur, J. OGD heartbeat: Cities' commitment to open data. J. Dem. Open Gov. 2015, 7, 116-136. [CrossRef]

37. Donker, F.W.; Loenen, B. How to assess the success of the open data ecosystem? Int. J. Digit. Earth 2017, 10, 284-306. [CrossRef]

38. Cecconi, G.; Radu, C.; European Commission; European Data Portal. Open Data Maturity in Europe 2018 (Rep.). 2020. Available online: https:/ / www.europeandataportal.eu/sites/default/files/edp_landscaping_insight_report_n4_2018.pdf (accessed on 13 November 2021).

39. Ahn, M.; Chu, S. What Matters in Maintaining Effective Open Government Data Systems? The Role of Government Managerial Capacity, and Political and Legal Environment. In Proceedings of the 22nd Annual International Conference on Digital Government Research (DG.O'21), Omaha, NE, USA, 9-11 June 2021; Association for Computing Machinery: New York, NY, USA; pp. 444-457. [CrossRef]

40. Linders, D. From e-government to we-government: Defining a typology for citizen coproduction in the age of social media. Gov. Inf. Q. 2012, 29, 446-454. [CrossRef]

41. Grimmelikhuijsen, S.G.; Feeney, M.K. Developing and Testing an Integrative Framework for Open Government Adoption in Local Governments. Pub. Admin. Rev. 2017, 77, 579-590. [CrossRef]

42. Grimmelikhuijsen, S.G.; Welch, E.W. Developing and Testing a Theoretical Framework for Computer-Mediated Transparency of Local Governments. Public Adm. Rev. 2012, 72, 562-571. [CrossRef]

43. Oliveira, G.H.M.; Welch, E.W. Social Media Use in Local Government: Linkage of Technology, Task, and Organizational Context. Gov. Inf. Q. 2013, 30, 397-405. [CrossRef]

44. Ma, L. Diffusion and Assimilation of Government Microblogging: Evidence from Chinese Cities. Pub. Manag. Rev. 2014, 16, 274-295. [CrossRef]

45. Moon, M.; Norris, D. Does managerial orientation matter? The adoption of reinventing government and e-government at the municipal level. Inf. Syst. J. 2005, 15, 43-60. [CrossRef]

46. Meijer, A.J. Understanding Computer-Mediated Transparency. Int. Rev. Admin. Sci. 2009, 75, 255-269. [CrossRef]

47. Layne, K.; Lee, J. Developing Fully Functional E-Government: A Four Stage Model. Gov. Inf. Q. 2001, 18, 122-136. [CrossRef]

48. Hall, R.H. The Concept of Bureaucracy: An Empirical Assessment. Am. J. Sociol. 1963, 69, 32-40. [CrossRef]

49. Damanpour, F. Organizational Innovation: A Meta-Analysis of Effects of Determinants and Moderators. Acad. Manag. J. 1991, 34, 555-590.

50. Mahler, J. Influences of Organizational Culture on Learning in Public Agencies. J. Public Adm. Res. Theory 1997, 7, 519-540. [CrossRef]

51. Bearfield, D.A.; Bowman, A.O. Can You Find It on the Web? An Assessment of Municipal E-Government Transparency. Am. Rev. Public Adm. 2016, 47, 172-188. [CrossRef]

52. Berry, F.; Berry, W. State Lottery Adoptions as Policy Innovations: An Event History Analysis. Am. Pol. Sci. Rev. 1990, 84, 395-415. [CrossRef]

53. Shipan, C.R.; Volden, C. The Mechanisms of Policy Diffusion. Am. J. Pol. Sci. 2008, 52, 840-857. [CrossRef] 
54. Berliner, D.; Erlich, A. Competing for Transparency: Political Competition and Institutional Reform in Mexican States. Am. Political Sci. Rev. 2015, 109, 110-128. [CrossRef]

55. Chau, K.; Tam, Y. Factors affecting the adoption of open system: An exploratory study. MIS Q. 1997, 21, 1-24. [CrossRef]

56. Walker, R.M. Internal and external antecedents of process innovation: A review and extension. Pub. Manag. Rev. 2014, 16, 21-44. [CrossRef]

57. Damanpour, F.; Walker, R.M.; Avellaneda, C.N. Combinative Effects of Innovation Types and Organizational Performance: A Longitudinal Study of Service Organizations. J. Manag. Stud. 2009, 46, 650-675. [CrossRef]

58. Relly, J.E.; Sabharwal, M. Perceptions of transparency of government policy-making: A cross-national study. Gov. Inf. Q. 2009, 26, 148-157. [CrossRef]

59. Jun, K.-N.; Weare, C. Institutional Motivations in the Adoption of Innovations: The Case of E-Government. J. Public Adm. Res. Theory 2010, 21, 495-519. [CrossRef]

60. McKinsey Global Institute. Digital Globalization: The New Era of Global Flows. 2016. Available online: https: //www.mckinsey.com/ \{\}/media/mckinsey/business\%20functions/mckinsey\%20digital/our\%20insights/digital\%20 globalization \%20the\%20new\%20era\%20of\%20global\%20flows/mgi-digital-globalization-full-report.pdf (accessed on 13 November 2021).

61. Lnenicka, M.; Komarkov, J. Developing a government enterprise architecture framework to support the requirements of big and open linked data with the use of cloud computing. Int. J. Inf. Manag. 2019, 46, 124-141. [CrossRef]

62. Vetrò, A.; Canova, L.; Torchiano, M.; Minotas, C.O.; Iemma, R.; Morando, F. Open data quality measurement framework: Definition and application to open government data. Gov. Inf. Q. 2016, 33, 325-337. [CrossRef]

63. Saxena, S. Summarizing the decadal literature in open government data research: A systematic review. Foresight 2018, 20, 648-664. [CrossRef]

64. Joshi, P.; Islam, S. E-Government Maturity Model for Sustainable E-Government Services from the Perspective of Developing Countries. Sustainability 2018, 10, 1882. [CrossRef]

65. Conradie, P.; Choenni, S. On the barriers for local government releasing open Data. Gov. Inf. Q. 2014, 31, 10-17. [CrossRef]

66. Braganza, A.; Brooks, L.; Nepelski, D.; Ali, M.; Moro, R. Resource management in big data initiatives: Processes and dynamic capabilities. J. Bus. Res. 2017, 70, 328-337. [CrossRef]

67. Yavuz, N.; Welch, E. Factors affecting openness of local government websites: Examining the differences across planning, finance and police departments. Gov. Inf. Q. 2014, 31, 574-583. [CrossRef]

68. Zhang, L.; Downs, R.R.; Li, J.; Wen, L.; Li, C. A Review of Open Research Data Policies and Practices in China. Data Sci. J. 2021, 20, 3. [CrossRef]

69. Wirtz, B.W.; Piehler, R.; Marc-Julian, T.; Daiser, P. Resistance of Public Personnel to Open Government: A cognitive theory view of implementation barriers towards open government data. Pub. Manag. Rev. 2016, 18, 1335-1364. [CrossRef]

70. Chatfield, A.T.; Reddick, C.G. The role of policy entrepreneurs in open government data policy innovation diffusion: An analysis of Australian Federal and State Governments. Gov. Inf. Q. 2018, 35, 123-134. [CrossRef]

71. Kaufmann, D.; Kraay, A.; Mastruzzi, M. The worldwide governance indicators: Methodology and analytical issues. Hague J. Rule Law 2011, 3, 220-246. [CrossRef]

72. Adnan, H.R.; Hidayanto, A.N.; Kurnia, S. Citizens' or Government's Will? Exploration of Why Indonesia's Local Governments Adopt Technologies for Open Government. Sustainability 2021, 13, 11197. [CrossRef]

73. Wang, H.; Lo, J. Adoption of open government data among government agencies. Gov. Inf. Q. 2016, 33, 80-88. [CrossRef]

74. Smith, M.L.; Seward, R.K. Open Government Data for Inclusive Development, Making Open Development Inclusive: Lessons from IDRC Research; MIT Press: Boston, MA, USA, 2020.

75. Zhang, N.; Zhao, X.; Zhang, Z.; Meng, Q.; Tan, H. What factors drive open innovation in China's public sector? A case study of official document exchange via microblogging (ODEM) in Haining. Gov. Inf. Q. 2017, 34, 126-133. [CrossRef]

76. Jing, Y. Study on the Influencing Factors of e-Government Service Capacity of Provincial Governments in China. Front. Edu. Res. 2020, 3, 12-15.

77. Clark, T.D.; Linzer, D.A. Should I use fixed or random effects? Political Sci. Res. Methods 2015, 3, 399-408. [CrossRef]

78. Lai-Yin, S.C.; Yuen-Ping, H. Effective industrial policy implementation for open innovation: The role of government resources and capabilities. Technol. For. Soc. Chang. 2020, 151, 119845.

79. Selznick, P. Institutionalism "Old" and "New". Admin. Sci. Q. 1996, 42, 240-277. [CrossRef]

80. Altayar, M. Motivations for Open Data Adoption: An institutional theory perspective. Gov. Inf. Q. 2018, 35, 633-643. [CrossRef]

81. Janssen, K. The influence of the PSI directive on open government data: An overview of recent developments. Gov. Inf. Q. 2011, 28, 446-456. [CrossRef]

82. West, J.; Bogers, M. Leveraging external sources of innovation: A review of research on open innovation. J. Prod. Innov. Manag. 2014, 31, 828-866. [CrossRef]

83. Kaufmann, D.; Kary, A.; Zoido-Lobotan, P. Aggregating Governance Indicators; Public Research Working Paper 2195; World Bank Development Research Group: Washington, DC, USA, 1999.

84. Zhao, Y.; Fan, B. Exploring open government data capacity of government agency: Based on the resource-based theory. Gov. Inf. $Q$. 2018, 35, 1-12. [CrossRef] 
85. Lee, S.Y.; Whitford, A.B. Assessing the effects of organizational resources on public agency performance: Evidence from the US federal government. J. Public Adm. Res. Theory 2013, 23, 687-712. [CrossRef]

86. Robertson, C.J.; Watson, A. Corruption and change: The impact of foreign direct investment. Strateg. Manag. J. 2004, 25, 385-396. [CrossRef]

87. Zhenbin, Y.; Kankanhalli, A.; Ha, S.; Tayi, G.K. What drives public agencies to participate in open government data initiatives? An innovation resource perspective. Inf. Manag. 2020, 57, 103179. [CrossRef] 